\title{
Local Historical Learning in Multicultural Education in The Era of Merdeka Learning
}

\author{
Ivan Prapanca Wardhana, Leo Agung S., Susanto \\ Universitas Sebelas Maret \\ ivanprapancawardhana@student.uns.ac.id
}

Article History

accepted 1/09/2020

approved 4/10/2020

published 1/12/2020

\begin{abstract}
History is a science that has a very big mission to improve human civilization, history provides many lessons about important concepts in facing the life to come. Multicultural education is a process of developing all human potential that respects plurality and heterogeneity as a consequence of cultural, ethnic, ethnic and religious (religious), economic, social, and political diversity. This study uses a literature study research method by collecting data from both document books, international and national journals, theses, proceeding articles, and websites related to the object of research then analyzed by text analysis techniques. As stated in the basic competencies in history lessons, it is implied to grow and instill multicultural education and national identity. Basically, national identity makes the hallmark of a nation which aims to instill character values and respect for the people in the culture and ethnic races that exist in Indonesia during the Free Learning era which is currently being implemented in the education system in Indonesia.
\end{abstract}

Keywords: Historical education, multicultural education, merdeka learning

\begin{abstract}
Abstrak
Sejarah adalah sebuah ilmu yang memiliki misi yang sangat besar untuk memperbaiki peradaban umat manusia, sejarah banyak memberikan pelajaran tentang konsep-konep penting dalam menghadapi kehidupan yang akan datang. Pendidikan multikultural merupakan proses pengembangan seluruh potensi manusia yang menghargai pluralitas dan heterogenitas sebagai konsekuensi keragaman budaya, etnis, suku dan aliran (agama), ekonomi, sosial, dan politik. Penelitian ini menggunakan metode penelitian studi pustaka dengan mengumpulkan data baik dari buku dokumen, jurnal internasional dan nasional, tesis, artikel prosiding, dan situs web yang berkaitan dengan objek penelitian kemudian dianalisis dengan teknik analisis teks. Seperti yang sudah dicantumkan dalam kompetensi dasar di pelajaran sejarah yang tersirat untuk menumbuhkan dan menanamkan pendidikan multikultural dan identitas nasional. Pada dasarnya identitas kebangsaan menjadikan ciri khas dari sebuah bangsa yang bertujuan untuk menanamkan nilai-nilai karakter serta menghargai masyarakat dalam budaya dan etnis ras yang ada di Indonesia dalam era Merdeka Belajar yang saat ini diterapkan dalam sistem pendidikan di Indonesia.
\end{abstract}

Kata kunci : Pendidikan sejarah, pendidikan multikultural, merdeka belajar

Social, Humanities, and Education Studies (SHEs): Conference Series https://jurnal.uns.ac.id/shes

p-ISSN 2620-9284

e-ISSN 2620-9292 


\section{PENDAHULUAN}

Multikulturalisme menurut Tariq Modood dalam Hoon, C. Y. (2013) adalah suatu istilah yang menarik. Hal tersebut dapat dipahami berbeda oleh banyak negara tergantung latar belakang sosial politik yang mengiringi kemunculan istilah ini. Seperti halnya dengan Negara Amerika Serikat, multikulturalisme diartikan secara politik digunakan untuk mengakui hak asasi manusia dan kesetaraan warga negara sebagai respon atas meningkatnya klaim atas perbedaan kelompok. Berbeda dengan Negaranegara Eropa, multikulturalisme adalah respon yang muncul dari imigrasi pendatang dari luar Eropa, dari orang non-kulit putih yang masuk ke negara-negara mayoritas kulit putih. Dalam hal ini, multikulturalisme berbentuk pengakuan atas kelompok- kelompok yang berbeda dalam ruang publik dan memiliki fokus yang lebih sempit yaitu berfokus pada konsekuensi imigrasi dan perjuangan dari beberapa kelompok marjinal.

Secara sederhana multikulturalisme berarti "keberagamaan budaya". Sebenarnya, ada tiga istilah yang sering digunakan secara bergantian untuk menggambarkan masyarakat yang terdiri keberagaman tersebut -baik keberagaman agama, ras bahasa, dan budaya yang berbeda- yaitu pluralitas (plurality), keragaman (diversity), dan multikultural (multicultural). Ketiga ekspresi itu sesungguhnya tidak merepresentasikan hal yang sama, walaupun semuanya mengacu kepada adaya 'ketidaktunggalan'.

Konsep pluralitas mengandaikan adanya 'hal-hal yang lebih dari satu' (many), keberagaman menunjukkan bahwa keberadaan yang 'lebih dari satu' itu berbeda-beda, heterogen, dan bahkan tak dapat disamakan. Dibandingkan dua konsep terdahulu, multikulturalisme sebenarnya relatif baru. Secara konseptual terdapat perbedaan signifikan anatara pluralitas, keberagaman, dan multikultural. Inti dari multikulturalisme adalah sebuah pandangan dunia -yang pada akhirnya diimplementasikan dan kebijakan- tentang kesediaan menerima kelompok lain secara sama sebagai kesatuan, tanpa mempedulikan perbedaan budaya, etnik, jender, bahasa, ataupun agama (Azra. 2007: 13.)

Pluralisme menurut Furnivall dalam Helmiati, H. (2013) mendefiniskan masyarakat plural sebagai comprising two or more dimana terdapat kehadiran dua atau lebih komunitas yang berbeda, tinggal berdampingan dalam satu unit politik, akan tetapi tidak saling berkait antara yang satu dengan yang lain; pembagian ekonomi berjalan seiring dengan pembagian budaya. Jadi masyarakat plural merupakan masyarakat yang memiliki lebih dari satu komunitas yang berbeda (beda bahasa, adat ataupun nilai sosial yang dianut), yang hidup berdampingan dalam suatu tatatanan pemerintahan seperti pemerintahan kerajaaan atau adat, namun antara komunitas yang satu dengan yang lain tidak saling terkait atau memiliki hubungan darah secara geneologis, setiap komunitas menjalankan kehidupan sosialnya masing-masing seperti memenuhi kebutuhan seharihari sampai pada menciptkan budaya sendiri.

Apabila pluralitas sekadar mempresentasikan adanya kemajemukan (yang lebih dari satu), multikulturalisme memberikan penegasan bahwa dengan segala perbedaannya itu mereka adalah sama di dalam ruang publik sehingga multikulturalisme menjadi semacam respons kebijakan baru terhadap keragaman. Dengan kata lain, adaya komunitas-komunitas yang berbeda saja tidak cukup, sebab yang terpentingadalah bahwa komunitas-komunitas itu diperlakukan sama oleh negara. Oleh karena itu, multikulturalisme sebagai sebuah gerakan menuntu pengakuan (politics of recognition)

C.W. Watson (2000) dalam bukunya Multiculturalism, membicarakan masyarakat multikultural adalah membicarakan tentang masyarakat negara, bangsa, daerah, bahkan lokasi geografis terbatas seperti kota atau sekolah, yang terdiri atas orang-orang yang memiliki kebudayaan yang berbeda-beda dalam kesederajatan. Pada hakikatnya masyarakat multikultural adalah masyarakat yang terdiri atas berbagai macam suku yang masing-masing mempunyai struktur budaya (culture) yang berbeda-beda. Dalam hal ini masyarakat multikultural tidak bersifat homogen, namun memiliki karakteristik 
heterogen di mana pola hubungan sosial anta rindividu di masyarakat bersifat toleran dan harus menerima kenyataan untuk hidup berdampingan secara damai (peace coexixtence) satu sama lain dengan perbedaan yang melekat pada tiap etnisitas sosial dan politiknya.

Pada dasarnya semua bangsa di dunia bersifat multikultural. Adanya masyarakat multikultural memberikan nilai tambah bagi bangsa tersebut. Keragaman ras, etnis, suku, ataupun agama menjadi karakteristik tersendiri, sebagaimana bangsa Indonesia yang unik dan rumit karena kemajemukan suku bangsa, agama, bangsa, maupun ras. Masyarakat multikultural Indonesia adalah sebuah masyarakat yang berdasarkan pada ideologi multikulturalisme atau Bhinneka Tunggal lka yang multikultural, yang melandasi corak struktur masyarakat Indonesia pada tingkat nasional dan lokal. Berkaca dari masyarakat multikultural bangsa Indonesia, kita akan mempelajari penyebab terbentuknya masyarakat multikultural.

\section{METODE PENELITIAN}

Penelitian ini menggunakan metode penelitian studi pustaka dengan mengumpulkan data yang berseumber dari buku, dokumen, jurnal internasional dan nasional, tesis, artikel prosiding, dan situs web yang berkaitan dengan objek penelitian kemudian dianalisis dengan teknik analisis teks (Wardhana, 2020). Sugiyono (2005: 83) mengungkapkan bahwa hasil penelitian akan semakin tinggi tingkat kredibillitasnya apabila didapatkannya dukungan berupa foto atau karya tulis akademik serta karya seni yang telah ada.

\section{HASIL DAN PEMBAHASAN \\ Konsep Penting dalam Pendidikan Multikultural}

Meninjau pendapat Andersen dan Cusher, bahwa pendidikan multikultural dapat diartikan sebagai pendidikan mengenai keragaman kebudayaan. James Banks mendefenisikan bahwa pendidikan multikultural sebagai pendidikan untuk people of color, artinya, pendidikan multikultural ingin mengeksplorasikan perbedaan sebagai keniscayaan (anugrah Tuhan/Sunatullah). Kemudian, bagaimana kita mampu mensikapi perbedaan tersebut dengan penuh toleran dan semangat. Pendidikan multikultural juga merupakan proses pengembangan seluruh potensi manusia yang menghargai pluralitas dan heterogenitas sebagai konsekuensi keragaman budaya, etnis, suku dan aliran (agama), ekonomi, sosial, dan politik.

Pendidikan multikultural (Multicultural Education) merupakan respon terhadap perkembangan keragaman populasi dalam sebuah institusi pendidikan, sebagaimana tuntutan persamaan hak bagi setiap kelompok. Dalam dimensi lain, pendidikan multikultural merupakan pengembangan kurikulum dan aktivitas pendidikan untuk memasuki berbagai pandangan, sejarah, prestasi dan perhatian terhadap orang-orang non Eropa, sedangkan secara luas, pendidikan multikultural mencakup seluruh peserta didik tanpa membedakan kelompok-kelompoknya seperti gender, etnis, ras, budaya, strata sosial, dan agama (Mahfud, 2006: 175-177).

\section{Sejarah Lokal Sebagai Pengantar Pendidikan Multikulturalisme}

Kesadaran sejarah merupakan bagian pengikat kesadaran multikulturalisme dalam suatu bangsa. Pendidikan sejarah berperan penting dalam internalisasi dan pembangunan kesadaran keberagaman. Pendidikan Sejarah Nasional Indonesia mempunyai maksud sebagai salah satu usaha penanaman kesadaran sejarah bangsa Indonesia pada peserta didik. Sejarah Nasional Indonesia selanjutnya diturunkan dalam Sejarah Lokal yang meliputi sejarah berbagai daerah di Indonesia dengan batasan administratif tertentu. 
Sejarah Lokal berfungsi untuk memperkuat Sejarah Nasional melalui penjabaran dan mengangkat peran suatu daerah dalam konstelasi Sejarah Nasional. Menurut Taufik Abdullah (1996: 15) sejarah lokal didefinisikan sebagai "sejarah dari suatu tempat", suatu locality yang batasannya ditentukan oleh perjanjian penulis sejarah. Penulis mempunyai kebebasan menentukan batasan penulisannya, apakah dengan wilayah kajian geografis, etnis, yang luas atau sempit. Sejarah lokal bersifat elastis, bisa berbicara mulai hanya mengenai suatu desa, kecamatan, kabupaten, tempat tinggal suatu etnis, suku bangsa yang ada dalam satu daerah atau beberapa daerah. Sejalan dengan pendapat ahli diatas, Mastrianto (2020: 810) turut menjelaskan bahwa Peristiwa sejarah lokal yang terdapat di lingkungan peserta didik memiliki peran sebagai unsur aktualisasi pembelajaran dan pendidikan.

Penulisan sejarah lokal mempunyai makna penting baik untuk kepentingan akademis maupun pembangunan masyarakat, terutama kepentingan masyarakat dalam mempelajari pengalaman masa lalu nenek moyangnya. Hal ini sejalan dengan yang diungkapkan Allan J. Ligthman (1978:169) "... local history conducted for their own sake, local history conduct to test hypotheses about broader jurisdictions, usually nation states, and local history that focus on understanding the process by which communities grow and develop. Although analytically distinct, in actual practise these lines frequently crisscross and run together."

Dalam bagian lain, Taufik Abdullah (1992: 239) menegaskan bahwa penulisan sejarah lokal begitu besar artinya dalam upaya pembahasan yang lebih detail tentang fenomena dan peristiwa nasional yang bersifat berkeping. Sejarah lokal diharapkan mampu memberikan sumbangan berupa kesadaran sebagai bangsa yang multi budaya, ditunjukkan dengan pengakuan akan kelemahan masing•masing dengan membangun kesederajatan di antara kebhinekaan. Dalam multikulturalisme diharapkan berlangsung iklim demokratis yang mampu mengakomodasi berbagai kepentingan dan perbedaan.

Salah satu perangkat efektif untuk mewujudkan kesadaran dan kesederajatan dalam keberagaman adalah konsep pendidikan multikultural. Selama ini belum ada mata pelajaran khusus multikulturalisme dalam pendidikan dasar dan menengah. Dengan demikian, sangat tepat apabila digunakan istilah pengajaran sejarah melalui pendekatan multikulturalisme. Tujuan pengajaran bukan sekedar transfer of knowledge, tetapi juga transfer of value, bukan sekedar membelajarkan peserta didik menjadi cerdas, tetapi juga berakhlak mulia (Supardi. 2006: 128).

Seperti yang sudah dicantumkan dalam kompetensi dasar di pelajaran sejarah yang tersirat untuk menumbuhkan dan menanamkan pendidikan multikultural dan identitas nasional, selain itu pengajaran sejarah bertujuan untuk mengembangkan keilmuan, juga mempunyai fungsi didaktis. Fungsi didaktis pengajaran sejarah telah dinyatakan secara implisit dan eksplisit, seperti yang dinyatakan Sartono Kartodirdjo (1992: 252) "bahwa maksud pengajaran sejarah adalah agar generasi muda yang berikut dapat mengambil hikmah dan pelajaran dari pengalaman nenek moyangnya". Nilai didaktik pengetahuan sejarah dalam pendidikan masa kini, selain bertujuan untuk membangkitkan kesadaran sejarah juga meningkatkan proses rasionalisasi serta melepaskan pikiran mitologis.

\section{Era Merdeka Belajar Sebagai Pengantar Pendidikan Multikulturalisme}

Nadiem Makarim (Tempo, 2019) menjelaskan bahwa guru adalah pemicu terlaksanya kemerdekaan berpikir pada peserta didik sehingga guru dalam melaksanakan proses penilaian kompetensi peserta didik dan menerjemahkan kompetensi dasar pada pembelajaran harus melalui proses interpretasi, refleksi dan proses pemikiran secara mandiri supaya dengan terjadinya proses refleksi dan meta kognitif pada guru maka barulah terjadi proses refleksi dan meta kognitif pada peserta didik. 
Merdeka belajar terlahir dari banyaknya permasalahan yang timbul dalam pendidikan, terutama yang terfokus pada pelaku atau pemberdayaan manusianya. Setelah diterapkannya kebijakan Merdeka Belajar, nantinya akan terjadi banyak perubahan terutama dari sistem pembelajaran. Sistem pembelajaran yang sekarang hanya dilaksanakan di dalam kelas akan berubah dan dibuat senyaman mungkin agar mempermudah interaksi antara peserta didik dan guru.

Salah satunya adalah kegiatan belajar dengan outing class, dimana kegiatan tersebut adalah salah satu program pembelajaran yang bertujuan untuk menumbuhkan kreativitas agar peserta didik memiliki keterampilan dan keahlian tertentu. Dalam kegiatan tersebut nantinya akan mempertemukan peserta didik dengan berbagai keragaman budaya, etnis, suku dan aliran (agama), ekonomi, sosial, dan politik. Sarana kegiatan pendidikan inilah yang nantinya akan memberikan pengenalan dan pemahaman peserta didik pada konsep pendidikan multikulturalisme karena peserta didik secara langsung bersinggungan dengan keberagaman yang ada.

Dari kegiatan tersebut guru mulai mengarahkan dan memberikan materi-materi mengenai pendidikan multikulturalisme terhadap peserta didik, proses refleksi dan meta kognitif pada guru yang telah terproses ini kemudian diteruskan kepada peserta didik tentang arti dan bagaimana pentingnya pendidikan multikulturalisme dalam kehidupan berbangsa dan bernegara.

\section{KESIMPULAN}

Pendidikan multikultural (Multicultural Education) merupakan respon terhadap perkembangan keragaman populasi dalam sebuah institusi pendidikan, sebagaimana tuntutan persamaan hak bagi setiap kelompok. Kesadaran sejarah merupakan bagian pengikat kesadaran multikulturalisme dalam suatu bangsa selain itu pendidikan sejarah berperan penting dalam internalisasi dan pembangunan kesadaran keberagaman terutama dalam pembelajaran Sejarah Lokal. Tujuan pengajaran bukan sekedar transfer of knowledge, tetapi juga transfer of value, bukan sekedar membelajarkan peserta didik menjadi cerdas, tetapi juga berakhlak mulia.

Dalam konsep pendidikan Merdeka Belajar terdapat kegiatan belajar dengan program outing class, dimana program pembelajaran ini bertujuan untuk menumbuhkan kreativitas agar peserta didik memiliki keterampilan dan keahlian tertentu. Dalam kegiatan tersebut nantinya akan mempertemukan peserta didik dengan berbagai keragaman budaya, etnis, suku dan aliran (agama), ekonomi, sosial, dan politik. Sarana kegiatan pendidikan inilah yang nantinya akan memberikan pengenalan dan pemahaman peserta didik pada konsep pendidikan multikulturalisme karena peserta didik secara langsung bersinggungan dengan keberagaman yang ada.

Dimana pada dasarnya identitas kebangsaan menjadikan ciri khas dari sebuah bangsa yang bertujuan untuk menanamkan nilai-nilai karakter serta menghargai masyarakat dalam budaya dan etnis ras yang ada di Indonesia dalam era Merdeka Belajar yang saat ini sudah mulai diterapkan dalam sistem pendidikan di Indonesia.

\section{DAFTAR PUSTAKA}

Abdullah, Taufik. 1992. Sejarah Lokal di Indonesia. Yogyakarta: Gadjah Mada University Press.

Azra, Azyumardi. 2007. Merawat Kemajemukan Merawat Indonesia. Yogyakarta: Institute Pluralism and Multikulturalism Studies (Impulse) dan Kanisius.

Helmiati, H. 2013. Dinamika Islam Singapura: Menelisik Pengalaman Minoritas Muslim di Negara Singapura yang Sekular \& Multikultural. Toleransi, Vol. 5(2), 87-99. 
Hoon, C. Y. 2013. Multicultural Citizenship Education in Indonesia: The Case of a Chinese Christian School. Journal of Southeast Asian Studies, Vol. 44(3), 490510.

Lichtman, Alan J., \& French, V. 1978. Historians and the Living Past: The Theory and Practice of Historical Study. Arlington Heights, III.: Harlan Davidson.

Supardi, S. 2006. Pendidikan Sejarah Lokal Dalam Konteks Multikulturalisme. Jurnal Cakrawala Pendidikan, Februari 2006, Th. XXV, No. 1.

Tempo.com. 13 Desember 2019. Nadiem Makarim: Merdeka Belajar adalah Kemerdekaan Berpikir. Diakses pada 03 Maret 2020.

https://nasional.tempo.co/read/1283493/nadiem-makarim-merdeka-belajar adalah-kemerdekaan-berpikir/

Mahfud, Choirul. 2006. Pendidikan Multikultural. Yogyakarta: Pustaka Pelajar. Mastrianto, A., Sariyatun, S., \& Suryani, N. (2020). Development of History-Based Digital Book Based on the 19th Century Lampung's People Army Struggle in Local History Lessons. Budapest International Research and Critics in Linguistics and Education (BirLE) Journal, 3(2), 809-819.

Watson, CW. 2000. Multiculturalism. London: Open University Press.

Wardhana, I. P. 2020. Konsep Pendidikan Taman Siswa sebagai Dasar Kebijakan Pendidikan Nasional Merdeka Belajar di Indonesia. Seminar Nasional Pendidikan, Maret 2020. Vol. 1, No. 1. 